\title{
Factors associated with insufficient removable partial denture design instructions
}

\section{Czynniki warunkujące niepełny przepływ informacji między lekarzem stomatologiem a technikiem podczas projektowania ruchomych częściowych uzupełnień protetycznych}

\author{
Nuran Özyemişci Cebeci ${ }^{A-F}$ \\ Dental Prosthesis Technology Program, Vocational School of Health Services, Hacettepe University, Ankara, Turkey \\ A - research concept and design; $\mathrm{B}$ - collection and/or assembly of data; $\mathrm{C}$ - data analysis and interpretation; \\ $D$ - writing the article; $E$ - critical revision of the article; $F$ - final approval of the article
}

\section{Address for correspondence \\ Nuran Özyemişci Cebeci}

E-mail: nozyemisci@yahoo.com

\section{Funding sources}

None declared

Conflict of interest

None declared

Received on February 14, 2018

Reviewed on March 6, 2018

Accepted on March 30, 2018

D0I

10.17219/dmp/89646

Copyright

○ 2018 by Wroclaw Medical University

and Polish Dental Society

This is an article distributed under the terms of the

Creative Commons Attribution Non-Commercial License

(http://creativecommons.org/licenses/by-nc-nd/4.0/)

\begin{abstract}
Background. The design of removable partial denture (RPD) has an important role in the health of dental and periodontal tissues. Dentists are responsible for the design since designing it requires mechanical and biological considerations. There is lack of literature focusing on the behavior of dentists in Turkey concerning the design of RPDS.
\end{abstract}

Objectives. This study aimed to assess the capability of dentists to transfer RPD design information to dental laboratories, and to determine the factors playing a role in the designing or transferring the design information.

Material and methods. A questionnaire was distributed to 25 dental laboratories in all geographical regions of Turkey. Design instructions of RPD provided by dentists using a prescription form, phone call and internet were examined. Clinic type, communication method, way of showing design information, and specialization in prosthodontics were recorded to investigate their association with design information. The data was analyzed with descriptive statistics and $x^{2}$ test.

Results. Approximately 2/3 of the dentists did not mention any design information in the instructions. Laboratory prescription form was the most frequently used communication method. Design features were mostly indicated in diagrams. The ratio of indicating design information was higher among prosthodontists. Over a half of the dentists who mentioned design information in their instructions were from private dental clinics. The dentists who preferred both writing and drawing for showing design specifications had the highest ratio of showing rest type, clasp location and rest location in their instructions.

Conclusions. The majority of dentists do not mention any design information. Expertise in prosthodontics and type of dental institution affect the content of the design information. Showing design features in more than 1 way seems to increase the amount of design items. Training dentists in aspects of RPD design and evaluating the circumstances of clinics is essential.

Key words: removable partial denture, denture design, dental laboratory

Słowa kluczowe: ruchome częściowe uzupetnienie protetyczne, projekt protezy, laboratorium dentystyczne 
Removable partial denture (RPD) is a comparatively economical and noninvasive option for prosthetic rehabilitation of partial edentulism. ${ }^{1}$ The design of RPD has an important role in the health of dental and periodontal tissues and the stability of the denture..$^{2-4}$ Designing an RPD necessitates mechanical and biological considerations, and requires clinical examination. Because of this concern, dentists are responsible for the RPD design as an ethical obligation. ${ }^{5-8}$ A proper transfer of design information to the dental laboratory provides increased professional quality assurance in an RPD service. ${ }^{5}$

Successful transfer of information regarding the details of prostheses to the dental technician plays an essential role in maintaining high quality of the prostheses. ${ }^{1,5}$ Methods of communication between dentist and technician are: authorization form, ${ }^{8-10}$ telephone call, ${ }^{8,9}$ e-mail, ${ }^{9}$ web-based communication, ${ }^{10,11}$ and text messaging. ${ }^{9}$ A growing body of literature has examined communication between the dentist and laboratory for fixed partial dentures and RPDs. Most of these studies have focused on the choice of impression trays and materials ${ }^{1,7,12-14}$ as well as quality of the written prescriptions. ${ }^{1,7,8,12-20}$ The studies that investigated the quality of the written prescriptions considered the following items: personal data of the patients, ${ }^{17-20}$ submission and completion date, ${ }^{16-18,20}$ fee, ${ }^{20}$ shade of teeth, ${ }^{16-20}$ material selection for prostheses, ${ }^{16-18}$ design information, ${ }^{7,8,13,16,17,19,20}$ and quality of the prescription (assessed as clear, a guide, poor, or none). ${ }^{1,7,12-17}$

According to the results of these investigations, the quality of the written prescriptions was often reported as poor ${ }^{1,7,13,14,17,19}$ and design of the prostheses was often delegated to the technician. $1,7,8,13-17,19,20$

Most studies about the communication concerned the quality of prescriptions. However, there is still a need for discussion on probable factors that may be responsible for delegating the design to the technician. Also, there is a lack of research addressing information on RPD design given by dentists in Turkey.

The first aim of this study was to investigate to what extent dentists in Turkey provide the dental technicians with adequate design information. The second aim was to determine whether there is a correlation between some conditions (professional training, type of dental institution, communication method, way of indicating design features) and adequacy of design information. A structured questionnaire on RPD design was developed for this study.

\section{Material and methods}

The target population of the study was identified as all members of dental technician unions or associations located in the 5 most populous cities in each of 7 geographical regions of Turkey (Aegean, Black Sea, Central Anatolia, Eastern Anatolia, Marmara, Mediterranean, and
Southeastern Anatolia). In Turkey, the dental technician associations and unions are independent institutions located in different cities. However, not all cities have such an institution. The laboratories located in the cities which do not have such an institution as well as the laboratories who did not fabricate RPDs were excluded from the study. Finally, the number of laboratories included in the study was 1 in the Aegean region, 2 in the Black Sea region, 3 in Central Anatolia, 1 in Eastern Anatolia, 2 in the Marmara region, and 2 in the Mediterranean region.

A pilot questionnaire was developed by the author to determine the adequacy of communication between dentists and dental laboratories in Turkey for RPD design and to examine probable factors affecting the adequacy of such communication. The pilot questionnaire was delivered to 7 dental laboratories, each located in a different geographical region, via e-mail. One-hundred seventeen pilot questionnaires were returned. A 6-item final questionnaire was designed to clarify the quantity and quality of design instructions from various categories of dentists and delivered to the target population with an invitation letter (Fig. 1).

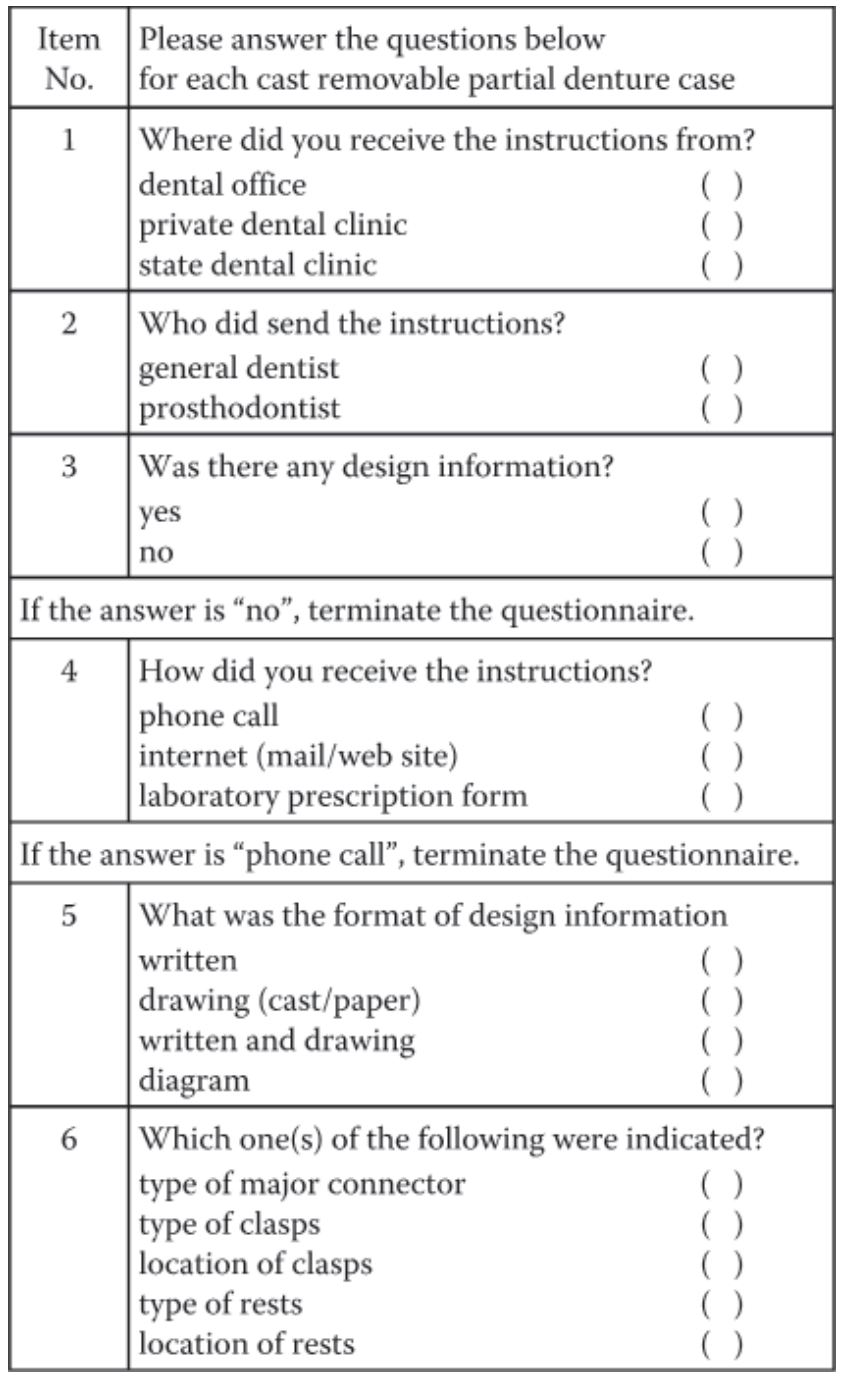

Fig. 1. Questionnaire 
Communication methods between dentists and dental technicians, including prescription forms, phone calls and internet messages, were examined. However, instructions from the dentist to the technician by phone call is not a reliable way of communicating, because oral instructions are liable to be subjectively interpreted. Consequently, such instructions were regarded as "no instructions" in the statistical analyses.

The survey was carried out within a time window of 2 months. The collected data was analyzed with descriptive statistics and then with $\chi^{2}$ test (SPSS v. 20 software; IBM Corp., Armonk, USA). Values of $\mathrm{p}<0.05$ were considered statistically significant.

\section{Results}

Eleven laboratories refused to participate in the study. Inconsistent responses from 2 laboratories were excluded. A total of 747 questionnaires were received from 25 laboratories from 8 cities (response rate $=66 \%$ ). Distribution of responses according to cities and geographical regions is shown in Table 1.

The majority of RPD orders were from state dental clinics $(60.8 \%)$ and general dentists (83\%). Only $37.5 \%$ of the dentists gave design instructions to the dental technicians as they were sending a master model or impression to the laboratory for RPD metal substructure casting. Filling a prescription form (85.7\%) was the most frequently preferred communication method to communicate with the technician and a diagram was the most preferred choice to indicate the design features (47.1\%). The type of clasp was the most common specification among design details (67.8\%) (Table 2).

Whereas $57.5 \%$ of the prosthodontists specified design information, only $33.4 \%$ of the general practitioners did so (Fig. 1). This difference was statistically significant $(\mathrm{p}<0.001)$.

Dentists from private dental clinics (56.9\%) were more likely to send RPD design information to a dental laboratory compared to dentists from dental offices (34.9\%) and state dental clinics (36.3\%) ( $\mathrm{p}=0.006)$ (Fig. 2).

Table 1. Distribution of survey responses

\begin{tabular}{|l|c|c|c|}
$\begin{array}{c}\text { Geographical } \\
\text { region }\end{array}$ & City & $\begin{array}{c}\text { Number } \\
\text { of responses }\end{array}$ & $\begin{array}{c}\text { Number } \\
\text { of laboratories }\end{array}$ \\
\hline Aegean & İzmir & 65 & 4 \\
Black Sea & Ordu & 78 & 3 \\
Conguldak & 282 & 5 \\
Eastral Anatolia & Ankara & 229 & 6 \\
Marmara & Eskişehir & 18 & 1 \\
Mediterranean & Elazı̆ & 33 & 2 \\
Total & Mersin & 22 & 2 \\
\hline
\end{tabular}

Table 2. Distribution of answers to the questionnaire

\begin{tabular}{|l|l|c|c|}
\hline \multicolumn{1}{|c|}{ Questions } & \multicolumn{1}{c|}{ Answers } & $n$ & $\%$ \\
\hline \multirow{3}{*}{ Institution } & dental office & 235 & 31.5 \\
& private dental clinic & 58 & 7.8 \\
& state dental clinic & 454 & 60.8 \\
Dental practitioner & general dentist & 620 & 83 \\
Design information & prosthodontist & 127 & 17 \\
& available & 280 & 37.5 \\
Communication method & not available & 467 & 62.5 \\
& phone call & 25 & 8.9 \\
& internet (mail/web site) & 15 & 5.4 \\
Format of design information & prescription form & 240 & 85.7 \\
& written & 53 & 20.8 \\
& drawing & 47 & 18.4 \\
& written and drawing & 35 & 13.7 \\
& diagram & 120 & 47.1 \\
& type of major connector & 120 & 52.9 \\
& type of clasps & 173 & 67.8 \\
Design specifications & location of clasps & 94 & 36.9 \\
& type of rests & 42 & 16.5 \\
& location of rests & 96 & 37.6 \\
\hline
\end{tabular}

$n$ - number of responses.

No significant correlation was identified between the method of providing design information and specification of the major connector $(\mathrm{p}=0.174)$ and clasp type $(\mathrm{p}=0.124)$. The correlation between the method of providing design information and specifying rest type, clasp location and rest location was statistically significant ( $\mathrm{p}<0.001$ for rest type; $\mathrm{p}=0.002$ for clasp location;

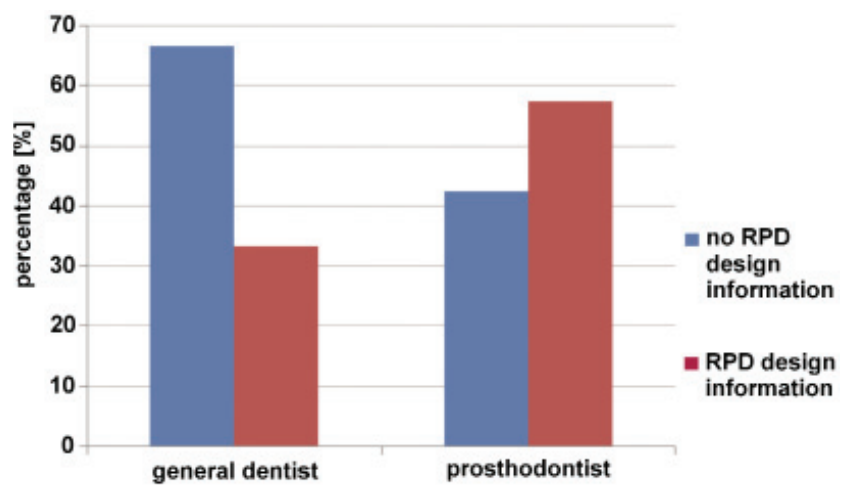

Fig. 1. Relationship between RPD design information and expertise

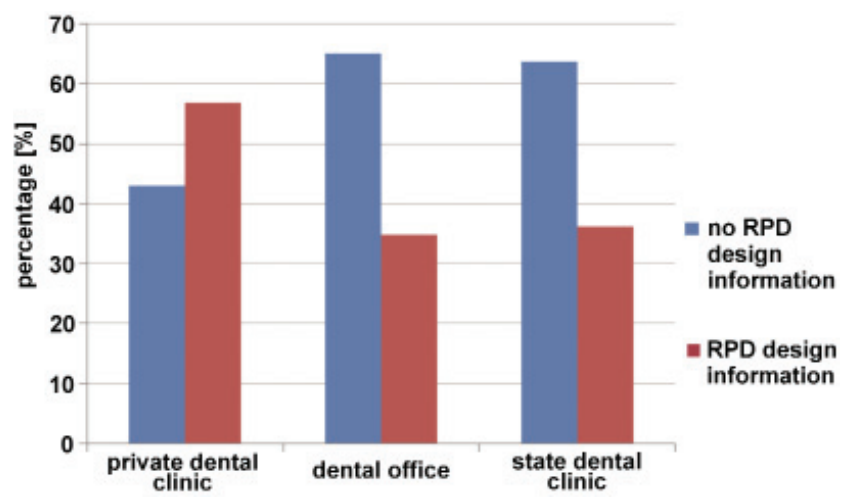

Fig. 2. Relationship between RPD design information and the type of clinic 
$\mathrm{p}<0.001$ for rest location). The prescription forms which included both written statements and drawn instructions had a higher ratio of data about rest type (48.6\%), clasp position (62.9\%) and rest position (71.4\%).

\section{Discussion}

Clear communication between the dentist and dental laboratory is an essential component of proper and highquality prosthetic rehabilitation. ${ }^{5}$ The present results indicate that the most common communication method between the dentist and the dental technician was a laboratory prescription form (85.7\%). This result is similar to the findings by Haj-Ali et al. in the United Arab Emirates. ${ }^{8}$ The role of RPD design in the success of the denture is an accepted fact. ${ }^{2,21,22}$ The results of this study showed that $62.5 \%$ of the dentists offered no design information when they sent a master model or impression to the laboratory for RPD fabrication. This result is higher than the findings of Kilfeather et al. (54\%, England, Ireland and Wales), Radhi et al. (57\%, Bahrain) and Pun et al. (42\%, Wisconsin, USA). ${ }^{1,13,23}$ In contrast, Haj-Ali et al. reported that $89.5 \%$ of laboratory prescriptions in the United Arab Emirates rarely or never provided design information. ${ }^{8}$ Lynch and Allen attributed inadequate design instructions to deficiencies in the vocational training of dentists. ${ }^{7}$ A similar conclusion may be drawn as a result of this study because of the positive correlation found between specialization in prosthodontics and design instructions. Higher professional education seems to have positive effects on dentists' awareness of the importance of RPD design information sent to the dental technicians. In view of the fact that the percentage of prosthodontists was only $17 \%$, the ratio of providing design information would be higher if more prosthodontists had contributed to the survey.

Most studies have determined the quality of RPD design instructions according to the scores given by technicians as "clear, a guide, poor, none"1,7,12-17 This kind of scoring may lead the technician to decide in a subjective manner. In the current study, to reduce the subjectivity of the technician, a question about RPD design elements was included. Details regarding type of the major connector was found in $52.9 \%$ of the instructions, which is lower than reported by Kilfeather et al. (62\%) and Sui et al. (88\%). ${ }^{1,19}$ In this study, detailed information about type of clasp was present in $67.8 \%$ of the instructions and location of clasp was found in $36.9 \%$. Sui et al. reported that $90 \%$ of the instructions included clasp design. ${ }^{19}$ Kilfeather et al. reported that $39 \%$ of direct retainers were described in the prescriptions. ${ }^{1}$ In this study, only $16.5 \%$ of the instructions showed type of rest and $37.6 \%$ of the instructions showed location of rest. Radhi et al. found that the percentage of the prescriptions regarding denture base, clasp design, rest design, and connector was $43 \%$ with 4 variables, $43 \%$ with 3 variables, $14 \%$ with 2 variables, and $43 \%$ with 1 variable. ${ }^{13}$
Dentists who work in private dental clinics more frequently gave design specifications than dentists who work in dental offices and state dental clinics. Further data collection is required to determine exactly how the type of clinic affects such information. One explanation why the design was not communicated to the dental technician might be excessive workload, causing the dentist to refrain from taking the necessary time to do so. Conditions of dental institutions may also lead lower percentages of details regarding major connector and clasp than similar studies mentioned above.

The ways dentists convey the design information to dental technicians was another issue examined in this research. The annotation document, which included both written statements and drawn instructions, had a higher ratio of data about rest type, clasp position and rest position. This could be attributed to the fact that more than 1 way of communicating was used, which might have motivated the dentist to give more details. However, in these documents, lack of specification of other RPD design features is still questionable. The results regarding the effect of the type of clinic and the way the design information was conveyed raises the question whether the problem is incompetence in designing the RPD or inadequacy in transferring design information. Further studies are needed to recognize the difference between the incapability of the dentist of making an appropriate RPD design and his/her incapability of transferring the design information to a laboratory even when he/she has adequate knowledge.

In this study, the results from the 8 cities were not analyzed separately. Further research may be undertaken including analyses of data for each city and comparison of the results among different localizations. However, dentists who work in a village/city lacking an RPD producing laboratory may post casts and instructions to other cities. This might influence the results.

Since a laboratory prescription form was the preferred communication method (85.7\%), the relevance between quantity of design specifications provided by dentists and the contents of present laboratory prescription forms can be researched in another study. Elaborating the contents of the form may encourage dentists to give more details about RPD design. Also, a diagram was the preferred choice to indicate the design features (47.1\%). Improved diagrams with more details may enable dentists to show more design features.

\section{Conclusions}

This study evaluated instructions for 747 RPDs made at 25 dental laboratories in 8 cities located in different regions of Turkey. More than a half of the dentists did not provide any design information. More prosthodontists than general dentists provided design information. The type of dental institution where the dentist works seems to have an effect on providing design information to the 
laboratory. Written and drawn design information is associated with better design specifications. This research can serve as a basis for future studies examining the determinants of poor RPD design information.

\section{References}

1. Kilfeather GP, Lynch CD, Sloan AJ, Youngson CC. Quality of communication and master impressions for the fabrication of cobalt chromium removable partial dentures in general dental practice in England, Ireland and Wales in 2009. J Oral Rehabil. 2010;37:300-305.

2. Itoh H, Baba K, Aridome K, et al. Effect of direct retainer and major connector designs on RPD and abutment tooth movement dynamics. J Oral Rehabil. 2008;35:810-815.

3. Preshaw PM, Walls AW, Jakubovics NS, Moynihan PJ, Jepson NJ, Loewy Z. Association of removable partial denture use with oral and systemic health. J Dent. 2011;39:711-719.

4. Aoda K, Shimamura I, Tahara Y, Sakurai K. Retainer design for unilateral extension base partial removable dental prosthesis by three-dimensional finite element analysis. J Prosthodont Res. 2010;54:84-91.

5. Carr AB, Brown DT. McCracken's Removable Partial Prosthodontics. $12^{\text {th }}$ ed. St. Louis, MO: Elsevier Mosby; 2011:119,284,287.

6. Dula LJ, Ahmedi EF, Lila-Krasniqi ZD, Shala KSh. Clinical evaluation of removable partial dentures on the periodontal health of abutment teeth: A retrospective study. Open Dent J. 2015;9:132-139.

7. Lynch CD, Allen PF. Quality of communication between dental practitioners and dental technicians for fixed prosthodontics in Ireland. J Oral Rehabil. 2005;32:901-905.

8. Haj-Ali R, Al Quran F, Adel O. Dental laboratory communication regarding removable dental prosthesis design in the UAE. J Prosthodont. 2012;21:425-428.

9. Berry J, Nesbit M, Saberi S, Petridis H. Communication methods and production techniques in fixed prosthesis fabrication: A UK based survey. Part 1: Communication methods. Br Dent J. 2014;217(6):E12.

10. Al Shiddi IF. Communication between dental office and dental laboratory: From paper-based to web-based. Pak Oral Dental J. 2014;34:555-559.

11. Alabduljabbar R, El-Masri S. Design of web content management system for dental laboratories. IJCSI. 2013;10:82-89.

12. Lynch CD, Allen PF. Quality of written prescriptions and master impressions for fixed and removable prosthodontics: A comparative study. Br Dent J. 2005;198:17-20.

13. Radhi A, Lynch CD, Hannigan A. Quality of written communication and master impressions for fabrication of removable partial prostheses in the Kingdom of Bahrain. J Oral Rehabil. 2007;34:153-157.

14. Afsharzand Z, Rashedi B, Petropoulos VC. Dentist communication with the dental laboratory for prosthodontic treatment using implants. J Prosthodont. 2006;15:202-207.

15. Afsharzand Z, Rashedi B, Petropoulos VC. Communication between the dental laboratory technician and dentist: Work authorization for fixed partial dentures. J Prosthodont. 2006;15:123-128.

16. Stewart CA. An audit of dental prescriptions between clinics and dental laboratories. Br Dent J. 2011;211(3):E5. doi: 10.1038/sj.bdj.2011.623

17. Parry GR, Evans JL, Cameron A. Communicating prosthetic prescriptions from dental students to the dental laboratory: Is the message getting through? J Dent Educ. 2014;78:1636-1642.

18. Dickie J, Shearer AC, Ricketts DN. Audit to assess the quality of communication between operators and technicians in a fixed prosthodontic laboratory: Educational and training implications. Eur $J$ Dent Educ. 2014;18:7-14.

19. Sui L, Wu X, Wu S, Gao P, Li R. The quality of written instructions for dental prostheses in China. J Prosthodont. 2014;23:602-609.

20. Carneiro LC. Specifications provided by practitioners for fabrication of removable acrylic prostheses in Tanzania. J Oral Rehabil. 2006;33:660-665.

21. Etman MK, Bikey D. Clinical performance of removable partial dentures: A retrospective clinical study. OJST. 2012;2:173-181.

22. Lynch CD. Successful removable partial dentures. Dent Update. 2012;39:118-120,122-126.

23. Pun DK, Waliszewski MP, Waliszewski KJ, Berzins D. Survey of partial removable dental prosthesis (partial RDP) types in a distinct patient population. J Prosthet Dent. 2011;106:48-56. 
